\title{
THE EFFECT OF INTRACRANIAL PRESSURE ON THE PER- FORMANCE OF AN APHASIC SUBJECT: A CASE HISTORY
}

\author{
MICHELLE SHAPIRO B.A. (SP. \& H. THERAPY) (WTTWATERSRAND) \\ Speech and Hearing Therapy Department. Baragwanath Hospital.
}

\section{SUMMARY}

\begin{abstract}
A battery of tests involving the language modalities of speech, comprehension, reading and writing were administered to an aphasic subject who presented with a predictable fluctuation in intracranial pressure. Results revealed a consistency in performance in the two situations, across all modalities. The subject's performance was found to be of a concrete nature, demonstrating a cognitive deficit concomitant with his linguistic impairment.
\end{abstract}

\section{OPSOMMING}

'n Battery toetse wat toetsing van die taalmodaliteite van spraak, begrip, lees en skryf insluit is uitgevoer op 'n afasiepatiënt wat gepresenteer het met 'n voorspelbare fluktuasie van intrakraniale druk. Resultate het konstantheid van gedrag in die twee situasies t.o.v. alle modaliteite aangetoon. Die pasiënt se gedrag was konkreet van aard, wat dui op die kognitiewe ontoereikendheid wat met 'n linguistiese afwyking gepaardgaan.

The performance of aphasics has been studied under the influence of alerting and tranquillizing drugs, fatigue induced by exercise, relaxation training, influence of motivating instructions and scheduling effects. ${ }^{18}$ One variable that has been given little consideration as to its potential influence on measurement of aphasic patients' communicative skills is intracranial pressure. The present study was concerned with the effects of changes in intracranial pressure on an aphasic subject's expressive and receptive language, reading and writing skills.

Schuell, Jenkins, and Jiminez-Pabon ${ }^{22}$ consider aphasia to be a general deficit that crosses all language modalities and which may or may not be complicated by other sequelae of brain damage. Marie and Goldstein ${ }^{16}$ believe that the principal form of the mental process is "symbolic activity", put into operation as "abstract" schemes, and thai every disease of the brain is manifested, not so much by loss of the ability to carry out specialized processes as by a depression of this symbolic function or abstract orientation. (p. 19).

Having stated these definitions it is opportune to pose two questions as yet unresolved in the literature. Is the aphasic patient impaired in his thinking because of a deficit in the language, or is he impaired in language because of a "primary, adventitiously acquired" deficit in thinking? ${ }^{10} \mathrm{~A}$ second question posed by Eisenson ${ }^{10}$ is particularly relevant to this study. Compared with his premorbid potential, is the aphasic an intellectually impaired person and so, at best, one who will continue to be linguistically impaired in that he will not recover fully his capacities for dealing with high-level abstract propositions? ${ }^{10}$ (p. 1224). Throughout the literature a general viewpoint emerges suggesting that the higher mental functions are formed in the process of ontogenesis, 
passing through several successive stages. ${ }^{11,12,}{ }^{16}$ Piaget $^{12}$ does not emphasize individual differences in intelligence, but has evolved a description of the general form of thought. His theories depict the optimum capabilities of thought at a given period in development. At successive stages in their development, the structure of the higher mental functions does not remain constant, but performs the same task by means of different, regularly interchanging systems of connections. ${ }^{16}$ Therefore, it can be concluded that reading, writing, receptive and expressive speech have different psychological compositions at different stages in development.

\section{METHODOLOGY}

AIM

The primary aim of the study was to determine the effect of intracranial pressure changes on the communicative skills (reading, writing, receptive and expressive language) of an aphasic subject.

The performance of the subject with variation in intracranial pressure (I.C.P.) was attained by testing the patient in the morning; that is, when the pressure had been built up after approximately eight hours sleep. In the afternoon the lower pressure recordings were made; that is, when the pressure had dropped after the day's activities in the upright position.

If no change is evident in the performance of the subject at high and low intracranial pressure, the writer will attempt to determine the possible contribution of a cognitive deficit to his linguistic impairment. It was hypothesized that the communicative skills will be improved when the intracranial pressure is at a higher level; and the converse; that is, that there is a detectable decline in performance when the pressure is lower.

\section{SUBJECT}

The subject used in this study was an English-speaking male, aged forty-nine years, who sustained an injury to his head when he fell six years before. A linear tempero-parieto-occipital fracture of the left hemisphere and a contrecoup lesion of the right frontal lobe was noted. A subdural haemorrhage developed on the left side. Within a week his head swelled and due to the excessively high I.C.P. he had to undergo an emergency, life-saving operation in which a haemotoma was removed. A bone flap was removed to provide adequate decompression. However, the decompression site became progressively more swollen, and a communicating hydrocephalus developed. As a result the I.C.P. rose to a danger level. The subject became semi-comatose, and in order to reduce this pressure, surgery was performed in which a ventriculo-atrial shunt was inserted. However, the opposite effect now occurred. Pressure manometry revealed a damped (low) I.C.P. system ( $5 \mathrm{ml} \mathrm{H}_{2} \mathrm{O}$ compared with the normal 130 $\mathrm{ml} \mathrm{H}_{2} \mathrm{O}$ ) with minimal rises in pressure with coughing, valsalva 
manoeuvre, speaking and posture. To ensure adequate circulation of blood through the brain a higher I.C.P. was required. Two further operations were performed. Firstly, a Stellon prosthesis was sutured to the bone and periosteum, thus separating the I.C.P. from the barometric (atmospheric) pressure and hence creating a closed system. In the second operation, an "on-off"' switch to the ventriculo-atrial shunt and an I.C.P. transducer were inserted. Pressure recordings were made with the valve switched "on" and "off".

In order to determine the relationship between the subject's I.C.P. and level of brain functioning, the relationship between the I.C.P. and fluid volume was established. A stress curve was used to act as a standard for the interpretation. This is represented in Figure 1.

In a normal subject, the cerebo-spinal fluid (C.S.F.) pressure is set to a steady level by externally induced forces, mainly from the respiration and less so from the heart.

To obtain Figure 1, controlled amounts of C.S.F. were first removed and then Ringer lactate solution added, with a pause at each station to allow the newly induced level to adjust spontaneously to a steady state, thus introducing three dimensional parameters of volume, pressure and

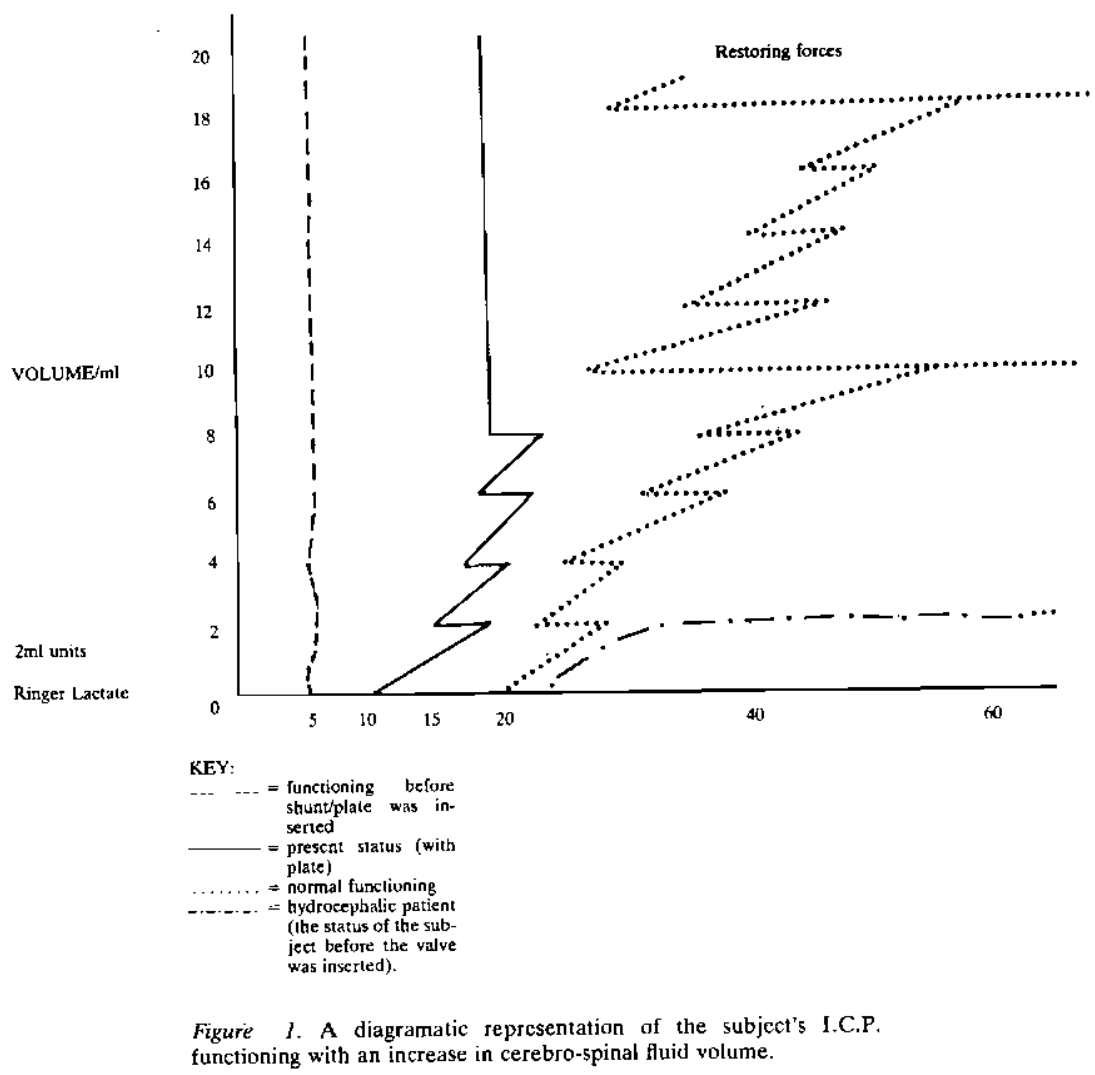


time. ${ }^{2,3} 2 \mathrm{ml}$ of fluid is injected at a time by means of a lumbar puncture and the rise in pressure is monitored. As can be seen in a normal subject each time $2 \mathrm{ml}$ is injected, the pressure rises. However, when a certain pressure is reached through stress or some other deviation, any increase in pressure can prove to be dangerous. The human copes with this by what has been termed restoring forces that oppose the distortion and reduce the pressure. The restoration appears to depend essentially on the overall elasticity of the system. Therefore, each stress curve is likely to be individual specific and pathology specific.

In the aphasic subject, by comparison, the shunt was originally overacting or overdraining and as a result the subject's opening pressure was about $5 \mathrm{ml} \mathrm{H}_{2} \mathrm{O}$. With the insertion of the plate the subject's opening pressure rose $5 \mathrm{ml} \mathrm{H}_{2} \mathrm{O}$ which is better than his previous one but below the normal opening pressure. Originally with an increase of volume, the pressure rose but then fell back to its original level. After a few increases in volume a further increase in volume did not result in a pressure increase.

The supine position facilitates the flow of blood to the brain. Upon rising in the morning the I.C.P. of the subject is at its optimum; that is approximating normal levels. Physiologically, this forms the basis for the improved functioning in the morning: the subject reported better performance in his speaking, reading, writing and comprehension. Owing to the valve function the I.C.P. reduces as the day progresses and consequently his performance declines. ${ }^{1}$

In this study the writer attempted to assess the reported changes in the subject's higher mental functions; that is, expressive and receptive speech, reading and writing skills.

TESTS

The battery of tests administered to assess the possible performance changes consisted of standardized and non-standardized tests. The standardized tests chosen had either test - retest reliability or equivalent forms in order to permit unbiased repeated examination of the same patient during conditions of high and low I.C.P. The Aphasic tests used which adhere to these criteria include the Boston Diagnostic Aphasia Examination, ${ }^{14}$ the Shortened Version of the Token Test ${ }^{6}$ and the Reporter's Test. ${ }^{7}$ The Neale Reading Analysis ${ }^{20}$ and Picture Story Language Test ${ }^{19}$ are also standardized tests. These were included in the battery, as reading and writing form part of higher cortical functioning. The abovementioned tests can be quantitatively and qualitatively analysed. The tests compiled by Penn ${ }^{21}$ were also included in the battery to assess the subject's competence with respect to complex sentences.

Finally, expressive samples of speech were analysed according to Crystal, Fletcher and Garman's ${ }^{4}$ language assessment, remediation and screening procedure (LARSP). The procedure was used to provide a description of the subject's syntactic output.

The South African Journal of Communication Disorders, Vol. 28, 1981 
To confirm the trends which emerged from the aforementioned battery, the Wechsler Intelligence Scale-for Children - Revised (WISC-R) was administered to assess the subject's verbal and non-verbal performances. ${ }^{24}$

\section{TESTING PROCEDURE}

With the exception of the WISC, each test or equivalent form of the test was administered on two separate occasions, with a week's interval. An hour was scheduled for each session to reduce the possibility of the subject becoming fatigued during the assessment period. Testing extended over ten days. One assessment was scheduled to be held in the morning at 8.30 ; that is, at the time of higher I.C.P. The second assessment was scheduled for the afternoon at 3.30 the following week. Order of scheduling, that is, morning first, afternoon second; and afternoon first, morning second, was randomly determined. (Refer Table I.)

An attempt was made to present approximately half the tests first in the morning and the other half first in the afternoon.

TABLE I: The testing procedure

\begin{tabular}{|c|c|c|}
\hline \multirow[b]{2}{*}{ Name of test } & \multicolumn{2}{|c|}{ Order of administration } \\
\hline & $\begin{array}{l}\text { Morning }(8,30 \text { a.m. }) \\
\text { Higher I.C.P. }\end{array}$ & $\begin{array}{l}\text { Afternoon }(3,30 \text { p.m. }) \\
\text { Lower I.C.P. }\end{array}$ \\
\hline$\frac{1}{2}$ Boston (first $\frac{1}{2}$ ) & 1st & 2nd \\
\hline$\frac{1}{2}$ Boston (second $\frac{1}{2}$ ) & 2nd & $1 \mathrm{st}$ \\
\hline $\begin{array}{l}\text { Shortened Version of the } \\
\text { Token Test }\end{array}$ & 2nd & 1 st \\
\hline Reporter's Test & $1 \mathrm{st}$ & 2nd \\
\hline $\begin{array}{l}\text { Complex sentences (com- } \\
\text { prehension and recall) }\end{array}$ & 2nd & 1 st \\
\hline $\begin{array}{l}\text { Description of an orange/ } \\
\text { banana }\end{array}$ & $1 \mathrm{st}$ & 2nd \\
\hline $\begin{array}{l}\text { How to attach a plug/ } \\
\text { change a tyre }\end{array}$ & 2nd & 1 st \\
\hline $\begin{array}{l}\text { Description of a picture } \\
\text { (from Boston Test) }\end{array}$ & $1 \mathrm{st}$ & 2nd \\
\hline Neale Reading Analysis & $1 \mathrm{st}$ & 2nd \\
\hline $\begin{array}{c}\text { Picture Story Language } \\
\text { Test }\end{array}$ & 2nd & $1 \mathrm{st}$ \\
\hline
\end{tabular}

Die Suid-Afrikaanse Tydskrif vir Kommunikasieafwykings, Vol. 28, 1981 


\section{RESULTS}

No marked difference in the subject's performance with higher and lower I.C.P. was evident from the battery of tests administered. (See Table II.)

On the Boston Diagnostic Aphasia Examination, the Z-Score profiles of Aphasia Subscores revealed a picture of "conduction aphasia" but showed little variation between measurements at higher and lower I.C.P.

On the Shortened Version of the Token Test, the subject performed better at times of lower I.C.P. on all parts of the test. Penn's comprehension subtest ${ }^{21}$ involved asking the subject questions about specific aspects of complex sentences presented orally. The subject displayed a consistent confusion of the deep relationship for each type of complex sentence as well as for sentences containing more than one embedding. The confusion of the deep relations was apparent at both the high and low I.C.P. performances, although the frequency of occurrence differed. Twenty-seven sentences were administered at each sitting, with a corresponding seventy-two questions. The subject's comprehension performance was found to be better at higher I.C.P.

The LARSP profiles revealed consistent performance of the subject at high and low I.C.P. in terms of the length of the sample; mean sentence length; distribution of the structures on the clause, phrase and word levels; number of expansions; and error types.

The results of the Complex Sentence-Recall Subtest were analysed qualitatively and indicated a better performance at low I.C.P.

On the Reporter's Test, no difference was found in the performance of the subject at high and low I.C.P.

Results from the Neale Reading Analysis revealed little change in performance at high and low I.C.P. on equivalent forms of the test. (Form B and Form C.)

The subject performed equally poorly at high and low I.C.P. on the Picture Story Language Test. On the abstract-concrete scale the subject obtained a score of " 6 " which falls within level II; that is, the "concrete-descriptive" level.

The WISC-R was administered only once, in the afternoon, to ascertain the relationship between the subject's verbal and non-verbal performances with respect to an age equivalent. Results revealed that he was functioning verbally on an 8 year 11 month level and non-verbally on an 11 year 10 month level.

\section{DISCUSSION}

The results of this study did not support the hypothesis that there is an improvement in performance at the time of higher I.C.P.

The subject's performance was consistent throughout the testing period regardless of the state of I.C.P. Although an improvement in 
TABLE II: Summary of the subject's performances at higher and lower I.C.P.

\begin{tabular}{|l|c|c|}
\hline \multicolumn{1}{|c|}{ Task administered } & High I.C.P. & Low I.C.P. \\
\hline The Boston Diagnostic Aphasia Examination & \pm & \pm \\
\hline The Shortened Version of the Token Test & + & - \\
\hline Complex sentences: comprehension & + & - \\
\hline Complex sentences: recall & - & + \\
\hline Description of an orange/banana & + & - \\
\hline Instructions: How to attach a plug/change a \\
tyre & \pm & \pm \\
\hline Reporter's Test & \pm & \pm \\
\hline Neale Reading Analysis & \pm & \pm \\
\hline Picture Story Language Test & \pm & \pm \\
\hline
\end{tabular}

\begin{tabular}{|c|c|c|}
\hline \multirow{2}{*}{\multicolumn{2}{|c|}{ Key: + }} & Improved performance \\
\hline & & Deteriorated performance \\
\hline & \pm & Consistent performance \\
\hline
\end{tabular}

comprehension performance was found with higher I.C.P., the amount of change was not marked.

Due to the fact that the neurosurgeon confirmed a physiological basis for improved performance, and the fact that the subject reported improved performance with higher I.C.P., it was important on the basis of the results to investigate the possibility of another factor contributing to the consistency in the subject's performance throughout testing. It was for this reason that the writer attempted to determine if the subject presented with a cognitive deficit concomitant with his linguistic impairment. Goldstein ${ }^{13}$ states that there is a change in an aphasic's behaviour in the ability to employ an abstract attitude. The essence of change is in a tendency towards concretism. ${ }^{9}$ (p. 1224.)

In Piaget's theory, the concrete-operational period takes place in the normal child between the ages of seven and eleven years, whereas the formal operational period (which he considers to be the final period of intellectual development) begins at about twelve years of age and is consolidated during adolescence. ${ }^{11,12}$ Inhelder and Piaget ${ }^{15}$ state that both the syntax and the semantics of 
language involve structures of classification. (p. 2.) As the subject performed poorly in both these areas, one would hypothesize that he experiences difficulty in "classification", and therefore, can attribute his poor performance to an underlying cognitive impairment.

An analysis based on the fact that not all word classes are understood in the same way, ${ }^{13}$ revealed that the subject experienced more difficulty understanding nouns than adjectives on the Shortened Version of the Token Test ${ }^{6}$ at lower I.C.P.

However, De Renzi and Vignolo ${ }^{8}$ assert that the nouns used in the Token Test, are, in fact, nouns which have the function of adjectives ("square" for example, identifies an attribute of the token, as does "red").

They forward a possible explanation for the difference in error count; namely, that shape is a more abstract concept than colour or size, and that geometrical conceptions and their linguistic equivalents are learned later than size and colour discrimination in childhood. This confirms the finding that the subject was operating at a concrete rather than an abstract level.

The subject's poor performance at high and low I.C.P. on the Complex Sentence-Comprehension Subtest illustrated clearly his inability to understand the meaning of complicated logico-grammatical combinations which express certain abstract relationships.

In analysing the six LARSP profiles of expressive speech it was found that the subject only used three subordinate clauses in the samples, and no instances of more than one subordinate clause in a particular utterance was evident.

Davelaar ${ }^{5}$ cited Bernstein who found a correlation between the amount of subordinate clauses that children use and the level of cognitive development. He suggested that a greater number of subordinate clauses implied a more advanced level of cognitive development.

The subject was unable to repeat sentences on both presentations of the Complex Sentence-Recall Subtest. Luria and Hutton ${ }^{17}$ postulate that the difficulty experienced in repeating as opposed to speaking, naming and understanding is due to the fact that repeating is an artificial task requiring certain abstractions that are not present in normal speech activity. They, therefore, assumed that the inability to repeat words or sentences is associated with an impairment of complex forms of abstract speech behaviour. Results of the Repórter's Test revealed a breakdown in the subject's ability to provide all the necessary information for a third person to reproduce the examiner's performance. This could be attributed to an impairment in cognition. A contemporary linguistic view is that writing is a parallel or alternative form of language to speech, and that reading, like listening, involves a direct "decoding to meaning", or comprehension. ${ }^{23}$

On the Neale Reading Analysis the subject obtained accuracy scores equivalent to a 7,1 and 8,6 year old respectively with high and low 
I.C.P., rate of reading scores of 6,11 and 7,2 years respectively and comprehension scores of 8,2 and 8,7 years respectively.

On the Picture Story Language Test (written) the subject's performance on both presentations of the test ranged between that of a 6 year old and an 11,5 year old.

As the results of this study revealed age equivalent scores between 6 and 11,5 years and qualitative interpretations revealed that the subject was performing on a concrete level, the writer administered the WISC-R to ascertain the relationship between the subject's verbal and non-verbal performances. Results of the WISC-R revealed that the subject is functioning at an 8,9 year old level verbally and at an 11,83 year old level non-verbally.

The overall results, therefore, indicate that all language modalities of the subject are impaired to about the same degree, and that the data is compatible with the assertion that there is a strong common factor underlying the impairments in each specific modality. Performances at all language modalities were strongly tied to concrete situations.

\section{CONCLUSION}

The quantitative and qualitative analyses of the battery of tests administered to the subject disproved the hypothesis that the communicative skills of the subject would be improved when his I.C.P. was at a higher level. However, the results illustrated that the subject was performing in the concrete-operational stage of Piaget's theory, thus supporting the possibility that there is a definite factor contributing towards the consistency in the subject's performance throughout testing; namely, a cognitive deficit concomitant with his linguistic impairment.

\section{ACKNOWLEDGEMENTS}

The author wishes to thank Ms. B. Jacks, Clinical Tutor, and Ms. C. Penn, Lecturer, in the Department of Speech Pathology and Audiology of the University of the Witwatersrand for their invaluable guidance and support, as well as Mr. K. L. Allen, the neurosurgeon, and the subject who participated in this study.

\section{REFERENCES}

1. Allen, K. L. (1980): Personal Communication.

2. Allen, K. L. (1971): A Study of the Pressure of the Cerebrospinal Fluid in Man by Remote Monitoring through the Skull Symposium on Biotelemetry. Pretoria.

3. Allen, K. L. and Goldman, N. I. (1967): Phasic Pressure Characteristics of the Cerebrospinal Fluid System South-Africa Journal of Surgery, 5(4), 151-158. 
4 Crystal, D., Fletcher, P. and Garman, M. (1976): The Grammatical Analysis of Language Disability: A Procedure for Assessment and Remediation. Edward Arnold.

5. Davelaar, E. (1977): Formal Operational Reasoning and its Relationship to Complex Speech Patterns and Tentative Statement Use. Language and Speech, 20, 73-79.

6. De Renzi, E. and Faglioni, P. (1978): Normative Data and Screening Power of a Shortened Version of the Token Test. Cortex, 14, 41-49.

7. De Renzi, E. and Ferrari, C. (1978): The Reporter's Test to Detect Expressive Disturbances in Aphasics, Cortex, 14, 279-293.

8. De Renzi, E. and Vignolo, L. A. (1962): The Token Test to Detect Receptive Disturbances in Aphasics. Brain, 85, 665-691.

9. Eisenson, J. (1971): Aphasia in Adults: Basic Considerations. In Handbook of Speech Pathology and Audiology. Travis, L. (Ed.), Appleton-Century-Crofts.

10. Eisenson, J. (1973): Adult Aphasia: Assessment and Treatment. Appleton-Century-Crofts.

11. Flavell, J. H. (1963): The Developmental Psychology of Jean Piaget. Litton Educational Publishing.

12. Ginsburg, H. and Opper, S. (1969): Piaget's Theory of Intellectual Development: An Introduction. Prentice-Hall.

13. Goldstein, K. (1948): Language and Language Disturbances. Grune and Stratton.

14. Goodglass, H. and Kaplan, E. (1972): Boston Test for Aphasia in the Assessment of Aphasia and Related Disorders. Lea and Febiger.

15. Inhelder, B. and Piaget, J. (1964): The Early Growth of Logic in the Child: Classification and Seriation. Routledge and Kegan Paul.

16. Luria, A. R. (1967): Higher Cortical Functions in Man. Basic books.

17. Luria, A. R. and Hutton, J. T. (1977): A Modern Assessment of the Basic Forms of Aphasia. Brain and Language, 4, 129-151.

18. Marshall, R. C., and Tompkins, C. A. and Phillips, D. S. (1980): Effects of Scheduling on the Communicative Assessment of Aphasic Patients. J. Comm. Dis., 13(2), 105-114.

19. Myklebust, H. R. (1965): Development and Disorders of Written Language: Picture Story Language Test. Vol. 1, Grune and Stratton.

20. Neale, M. D. (1966): Neale Analysis of Reading Ability. St. Martin's Press.

21. Penn, C. (1974): A Linguistic Approach to the Detection of Minimal Language Dysfunction in Aphasia. J. S. A. Speech \& Hear Assoc. 21, 3-20.

22 Schuell, H., Jenkins, J. J. and Jimenez-Pabon, E. (1964): Aphasia in Adults. Harper and Row. 
23. Smith, F. (1975): Relation Between Spoken and Written Language. In Foundations of Language Development: A Multidisciplinary Approach. Vol. 2. Lennenberg, E. H. and Lennenberg, H. (Eds.) Academic Press.

24 Wechsler, D. (1974): Wechsler Intelligence Scale for ChildrenRevised. The Psychological Corporation. 